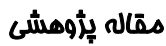

\section{بردسى الكوهاى يردازش حسى كودكان اوتيسم Y Y-V سال از ديدكاه معلمان}

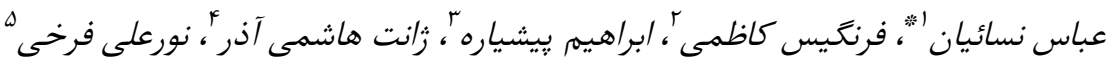

' دانشجوى دكترى تخصصى روانشناسى و آموزش كودكان استثنايى، دانشكده روانشناسى و علوم تربيتى، دانشكاه علامه طباطبايى، تهران، ايران

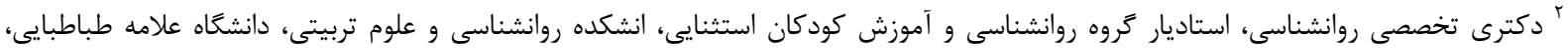
تهران، ايران

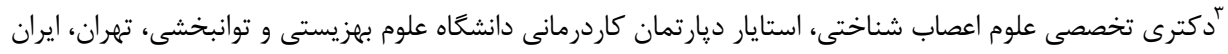

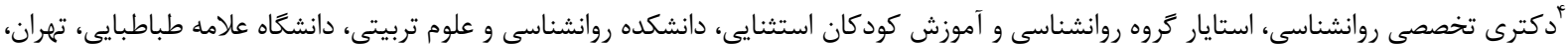
ه دكترى تخصصى روانشناسى تربيتى، استاديار كروه روانشناسى تربيتى و روانسنجى، دانشكده روانشناسى و علوم تربيتى، دانشكاه علامه طباطبيى، تهران، ايران تنويسنده مسئول: دانشجوى دكترى تخصصى روانشناسى و آموزش كودكان استثنايى، دانشكده روانشناسى و علوم تربيتى، دانشخاه علامه طباطبايى، تهران، ايران يست الكترونيك: Anesayan1@gmail.com

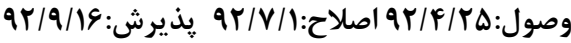

جكيده زمينه و هدف: افراد براى كاركرد مناسب در محيط و شركت در فعاليتهاى روزانه زندكى به توانايى بردازش حسى مناسب نياز دارند.

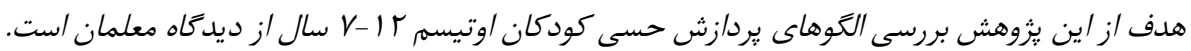

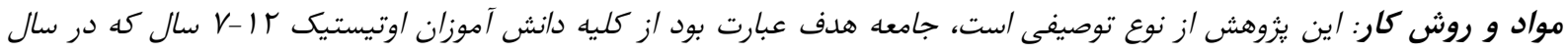

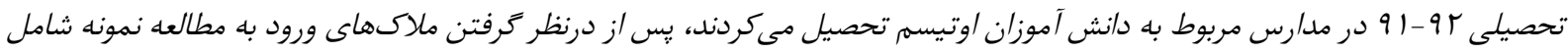

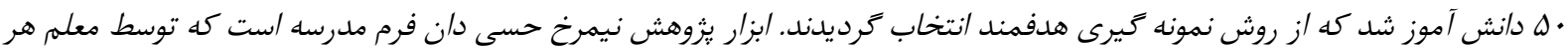

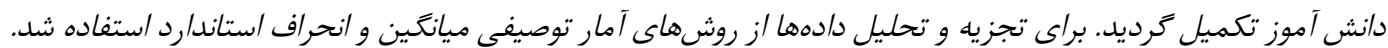

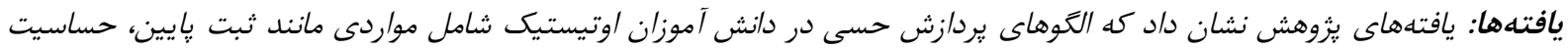

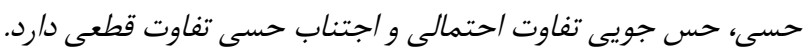

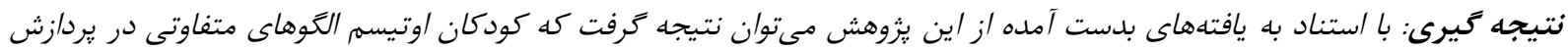
حسى دارند. وازههاى كليدى: الكوى بردازش حسى، كودكان /وتيسم

ناتوانى رشدى است كه به طور معنادارى بر ارتباط كلامى مقدمه

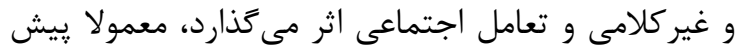

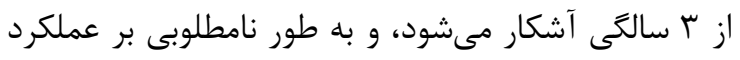

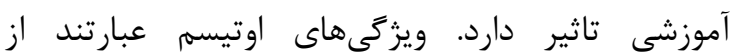
نابهنجارى و نارسايى در ارتباط، يرداختن به فعاليتهاى

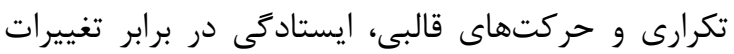

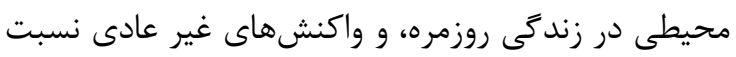
به تجربههاى حسى [ץ]. راهنماى تشخى رونيصى و و آمارى

1 - Autism

2 - Kaner

3 - Autism spectrum disorder
در سالهاى اخير توجه بىسابقهاى در عرصه عمومى و

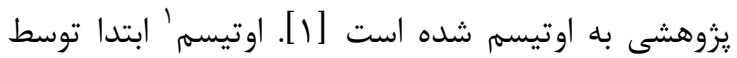

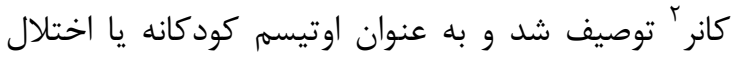

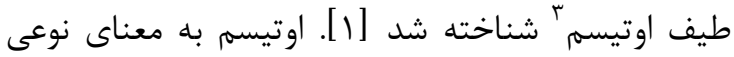


مدل يردازش حسى دان شامل دو سازه مىشود كه عبارتند از: ا- سازه اول آستانههاى عصب شناختى استى

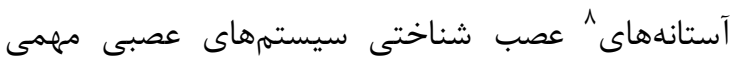
هستند كه براى درك يردازش حسى ايجاد شداد شدهاند. آستانه

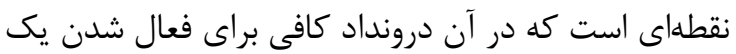
سلول عصبى يا سيسته وجود دارد. موقعى كه محرك كها به دانه

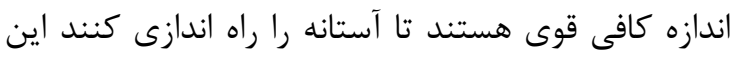

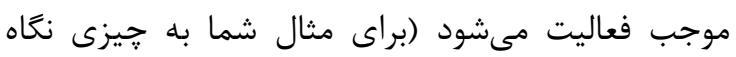

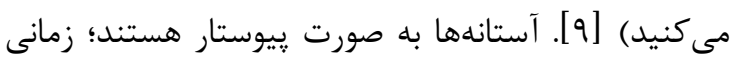

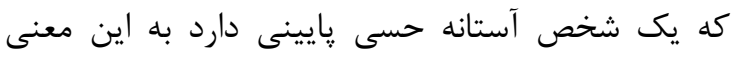

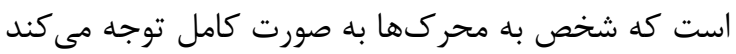
و ياسخ خواهد داد جرا كه سيستم به سادگى با اين وقايع حسى فعال مىشود. زمانى كه يك شخص آستانه بالايى

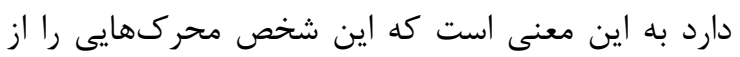
دست مىدهد كه افراد ديكر به آسانى به آن توجين آنه مى كنند زيرا به محرك هاى قوى ترى براى فعال شدن نياز دارد. هر شخص براى توجه كردن و پاسخ دادن به وقايع

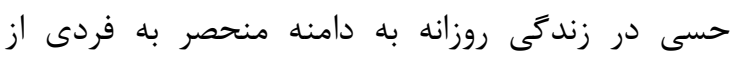

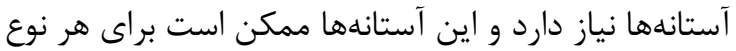
از درونداد حسى متفاوت باشد. براى مثال يكى فرد ممكن آنان است به سادگى به صداها توجه كند (براى مثال آستانه קايين براى صدا) اما ممكن است به ساير محركها به سادگى توجه نكند مانند لمس كردن (براى مثال ممكن

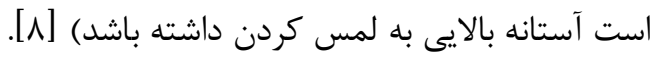
ץ- سازه دوم خود است كه روى يك يِيوستار (منفعل-فعال) قرار دارد.

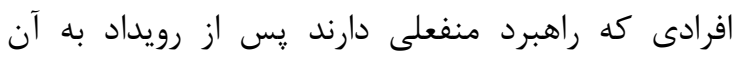

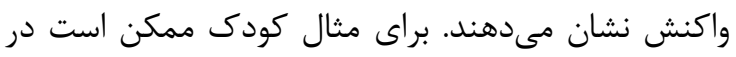
طول بازى به نشستن در بين دو كودى ديكر ادامه دهد

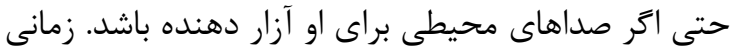

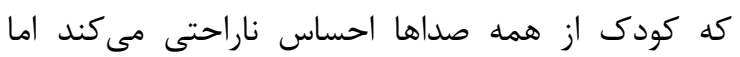

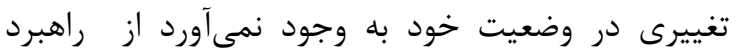
خودكردانى منفعل استفاده مى كند. در انتهاى ديخر اين

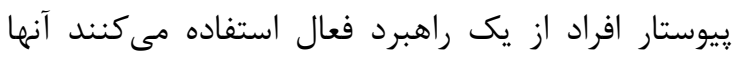

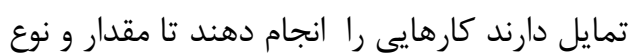

8 -threshold

9 - self-regulation
اختلال هاى روانى(DSM-IV) تجارب حسى غير معمول

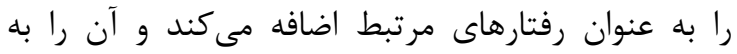

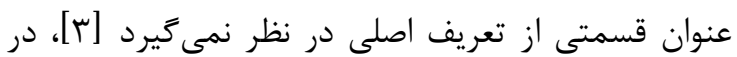

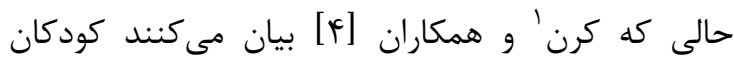
اوتيسم علاوه بر اين كه با نقص در ارتباط و اجتماعى

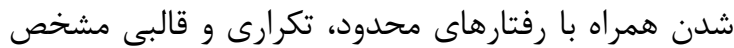
مىشوند، ويزگى هاى بالينى شامل مشكل در توجه، جالش با رفتارهاى آشناو مشكل بردازش حسى نئ نيز دارند. يردازش حسى به شيوهاى اشاره دارد كه سيستمهاى

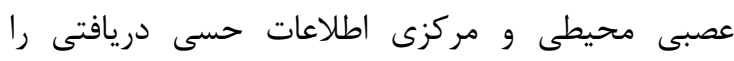

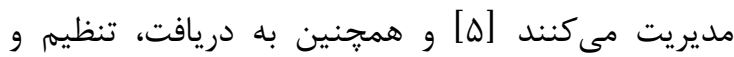
انسجام اطلاعات حسى به صورت متوالى و توليد "باسخ

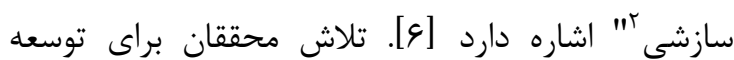

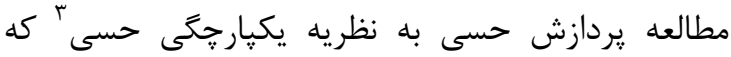

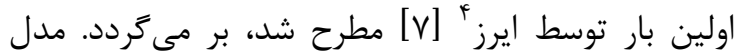

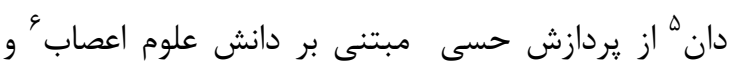

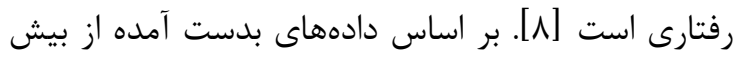

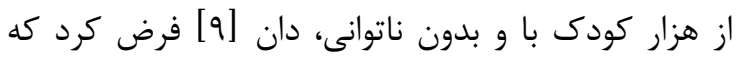

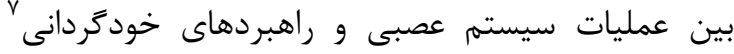
ارتباط وجود دارد و تعامل اين كاركردها الكوهاى اساسى إسى

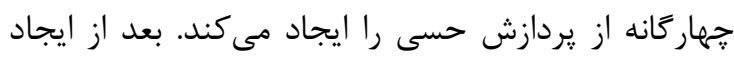

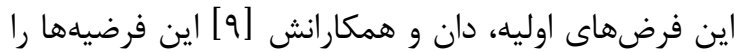
درباره الكوهاى اساسى يردازش حسى در تروههاى سنى

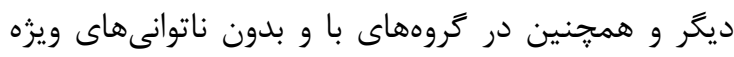

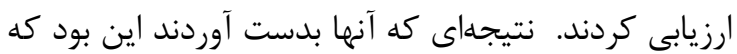

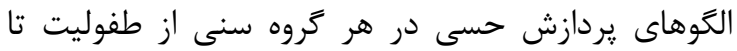

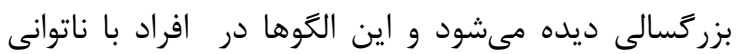

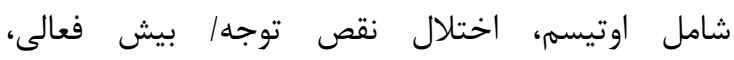

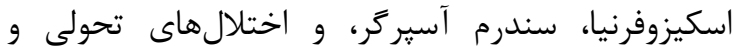

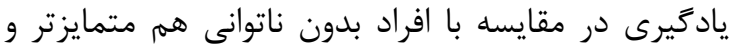
هم شديدتر است [9].

1 - Kern

2 - Adaptive response

3 - sensory integration theory

4 -Ayres

5 - Dunn's Model

6 - Neuroscience

7 - Self-regulation 
جدول ا: مدل يردازش حسى دان [q]. راهبرد خودَردانى /ياسخ هاى رفتارى

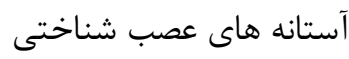

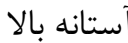

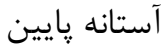

منفعل

ثبت پايين

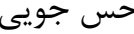

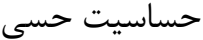

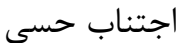

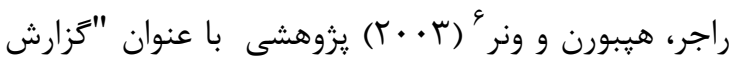

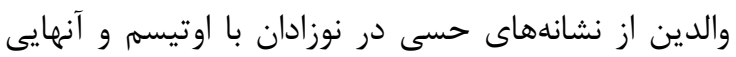

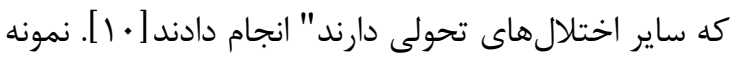

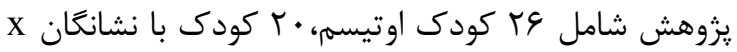

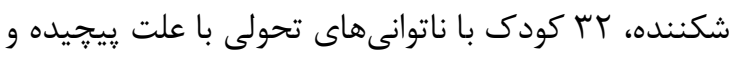

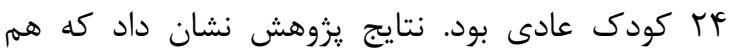
كودكان اوتيسم و هم كودكان با نشانكان X شكننده به

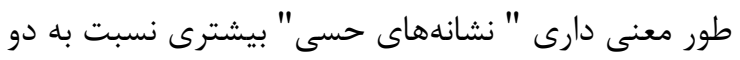

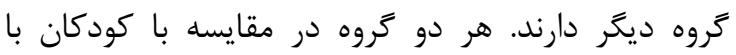

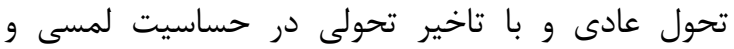
يالايش شنيدارى بيشتر آسيب ديدهاند. كودكان اوتيسم

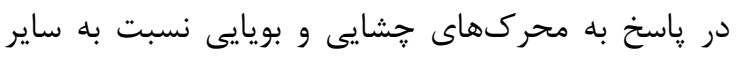
كروهها ناهنجارى بيشترى نشان مى دهند.

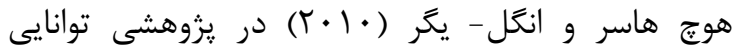

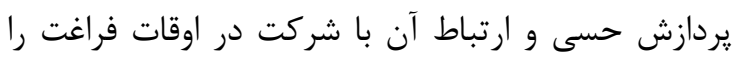
در بين كودكان با اختلالهاى طيف اوتيسم با كاركرد بال بالا

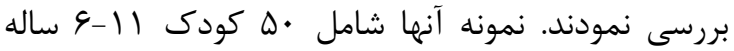

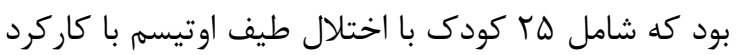

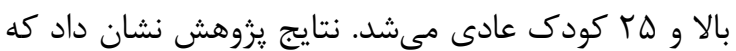

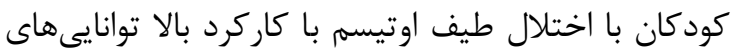

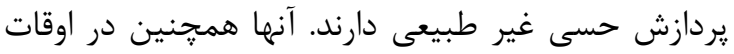

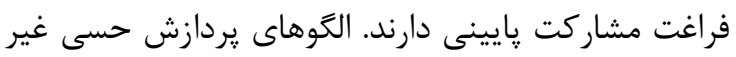

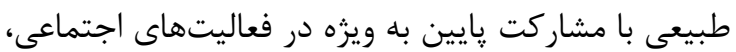
جسمانى و غير رسمى رابطه دارد [11].

6 - Roger, Hepburn \& Wehner
دروندادى را كه برايشان در دسترس است كنترل كنند.

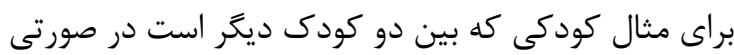
كه صداها آزار دهنده باشند به يك مكان آرامتر خواهد دئ داند

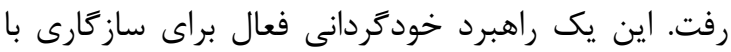

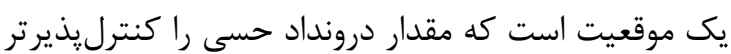

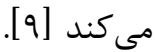
هنكامى كه اين دو ييوستار به هم وصل مىشوند، جهار

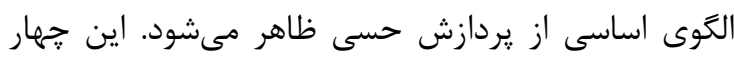

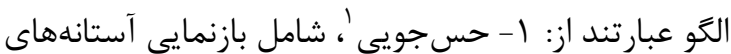

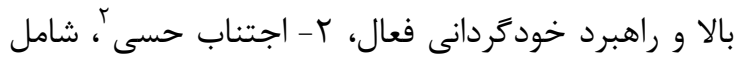
آستانههاى يايين و راهبرد خود خردانى فعال، ب- حساسيت

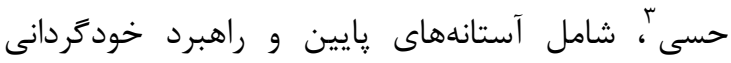

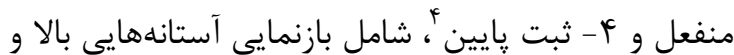

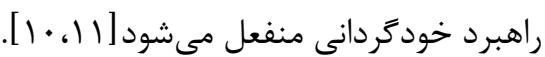
از زمانى كه دان [^] مدل يردازش حسى مدى رانى را ارائه كرد يزوهشهاى بسيارى در اين زمينه صورت گَرفته است،

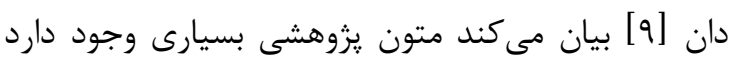
كه يردازش حسى را در كودكان توصيف مى كنند و اهميت

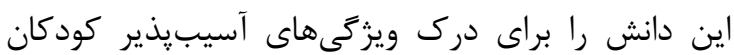
ييشنهاد مى كند. در ذيل برخى از يزوهشهاى صوري

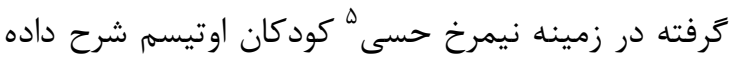

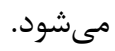

1 - sensation seeking

2 - sensation avoidance

3 - sensation sensitivity

4 - low registration

5 - sensory profile 
ديخرى در اين زمينه صورت نخرفته است. با توجه به

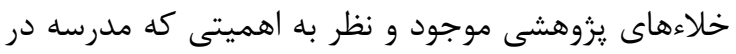
يادگيرى دانش آموزان دارد، اين يزوهش به به دنبال آن است

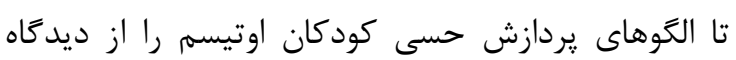

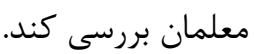

روش كار

روش يزوهش اين مطالعه توصيفى است. جامعه آمارى اين

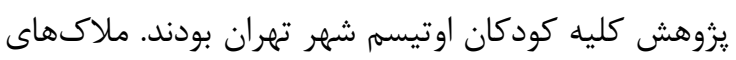

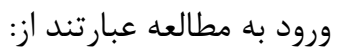

1- داشتن اوتيسم براساس تشخيص روانيزشك متخصص

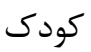

ז- كودكان اوتيسم بدون داشتن نقايص حسى (مانند ناشنوايى يا نابينايى)، جسمى و جند اند معلوليتى.

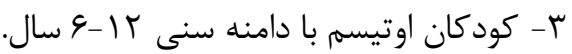

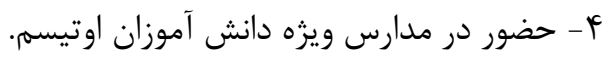

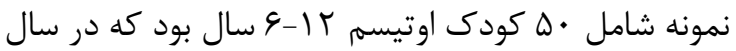
تحصيلى ז9-|9 || مشغول به تحصيل بودند.

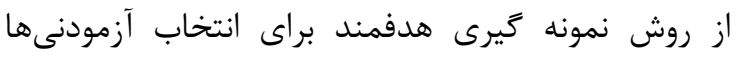

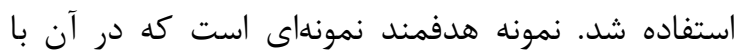

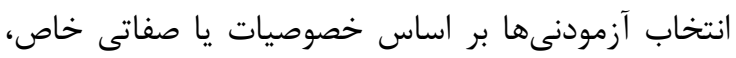

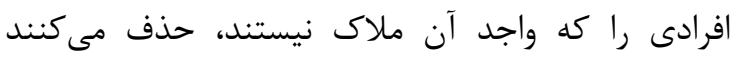

[19]

در اين يزوهش براى بررسى الكوهاى يردازش حسى از

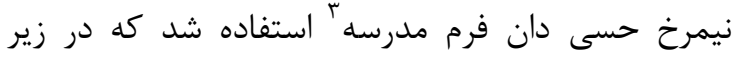
توضيح داده مىشود. اين نيمرخ توسط دان (1997) تهيه شده است. نيمرخ حسى فرم مدرسه يك ابزار اندازه كيرى استاندارد شده

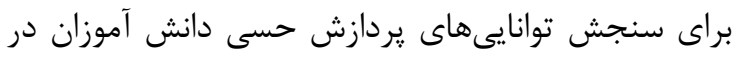

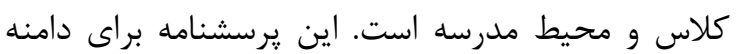

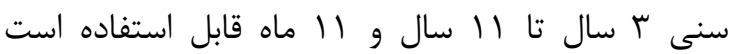

$$
\text { اجراو نمره كذارى }
$$

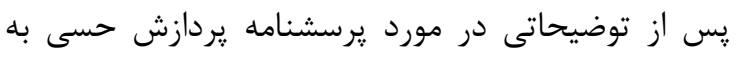

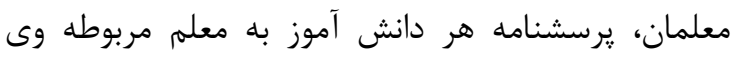
داده شد تا آن را تكميل نمايند.

3 - sensory profile school companion

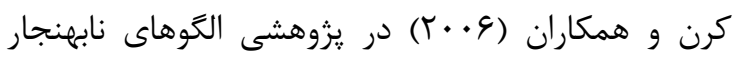
يردازش حسى را در كودكان اوتيسم بررسى نمودند. نمونه

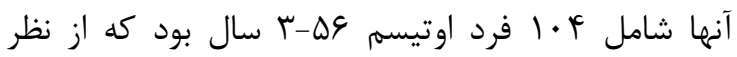
سنى با كروه كنترل همتا شده بودند. نتايج نشان داد افراد

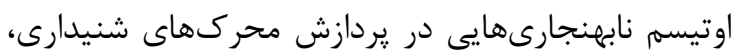

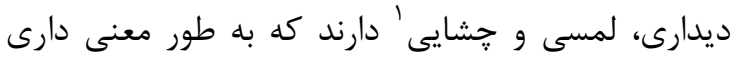

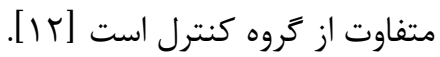

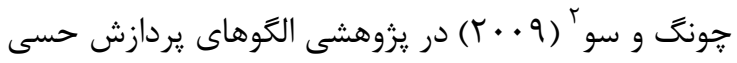
حسى را در كودكان با و بدون ناتوانىهاى تحولى مقايسه

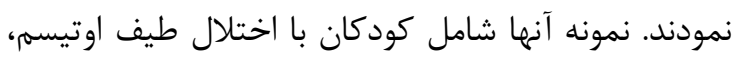
اختلال نقص توجه/بيش فعالى و كودكان بدون ناتوانى بود.

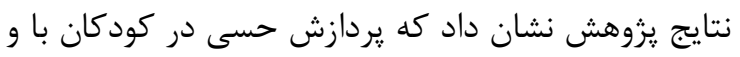
بدون ناتوانى متفاوت است، اما تشخيص تفاوت در يردازش

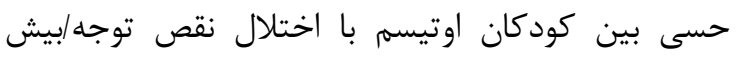

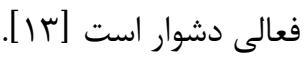
يردازش حسى به دريافت، تنظيم و انسجام اطلاعات حسى

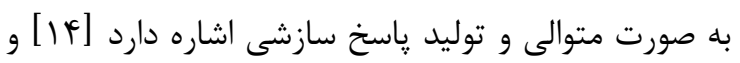

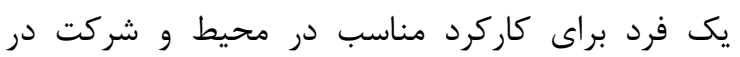

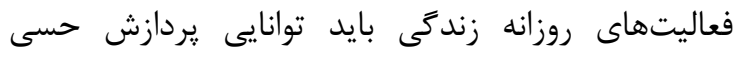

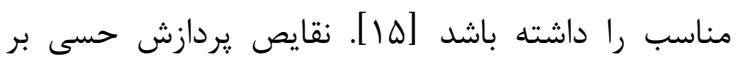

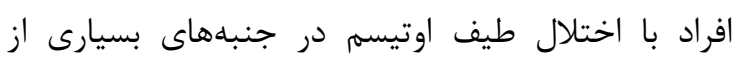

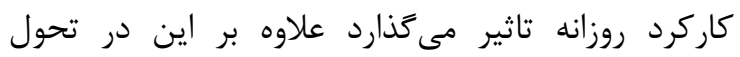

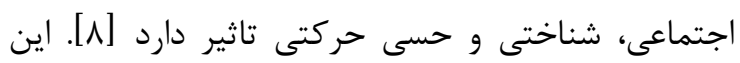

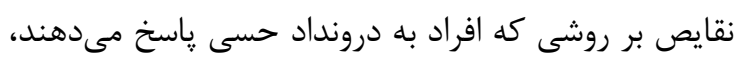

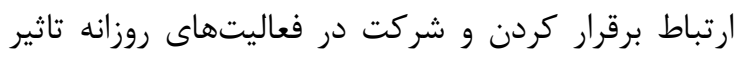

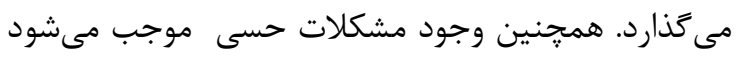

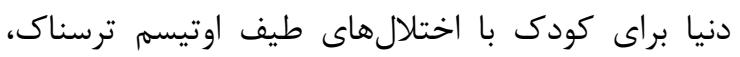

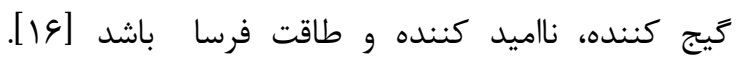
اجتناب از موقعيتهاى اجتماعى مشخص، ممكن است با

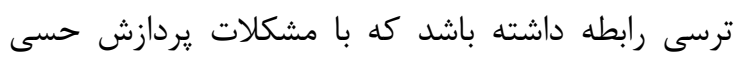

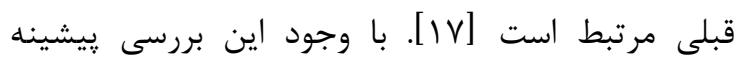
يزوهشى در كشور نشان مىدهد كه كه در اين حيطه

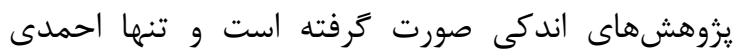

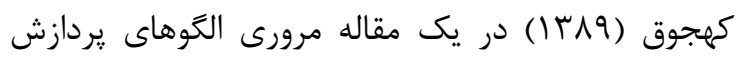

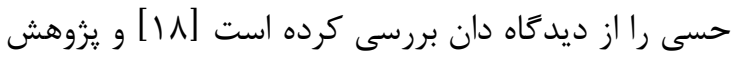


الكوهاى يردازش حسى كودكان اوتيسم از ديدگاه معلمان

$$
\text { جكَونه است؟ }
$$

براى تجزيه و تحليل اين سوال از آمار توصيفى ميانحين و

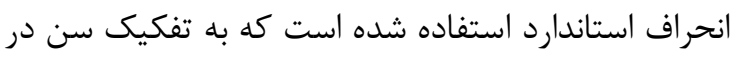

$$
\text { جدول سارائه شده است. }
$$

قبل از ارائه نتايج تجزيه و تحليل لازم به ذكر است كه استه

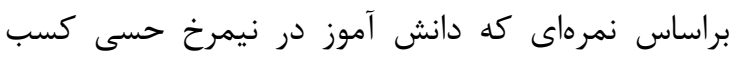

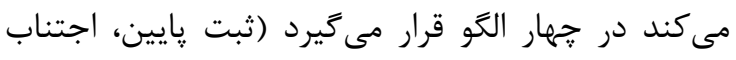

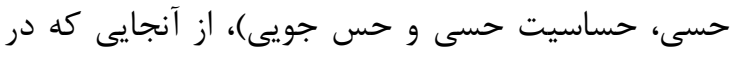

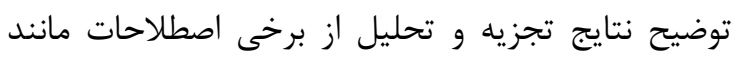

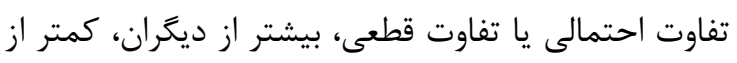

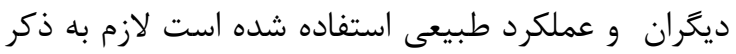

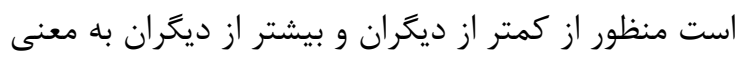

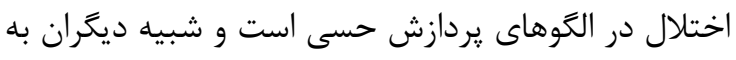

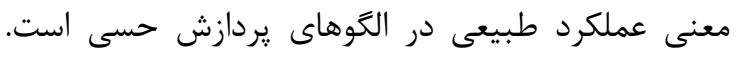

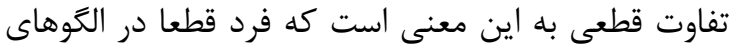

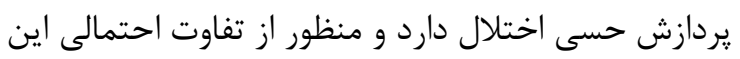

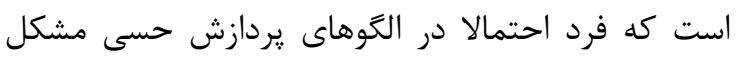

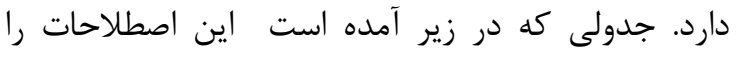

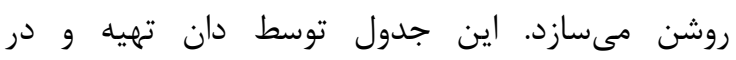
دستورالعمل (كتابحه) آزمون آمده است.

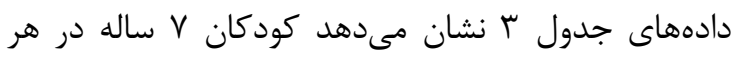
جهار الكوى حسى تفاوت احتمالى دارند، يعنى مشكلات آندات

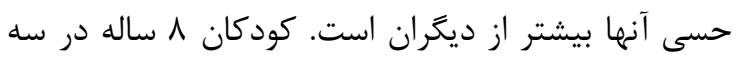

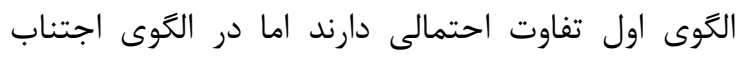

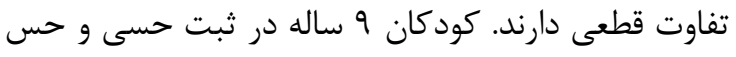

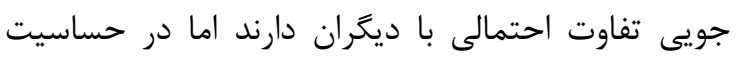
حسى و اجتناب حسى تفاوت قطعى با ديكران دارند. كودكان • ا ساله در سه الكوى اول تفاوت احتمالى دابل دارند

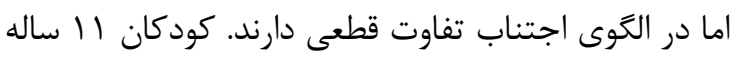

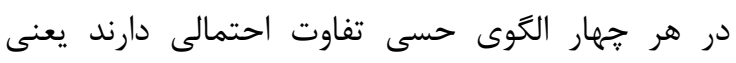

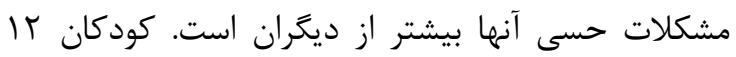

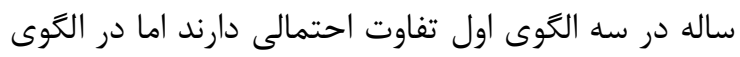

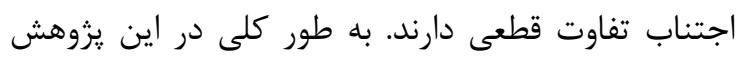

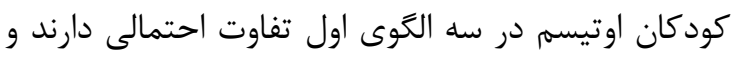
در اجتناب حسى تفاوت قطعى با ديكران دارند.
نمره كذارى يرسشنامه به صورت ليكرتى (تقريبا هميشه،

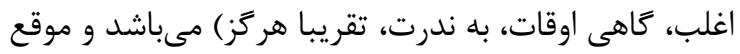

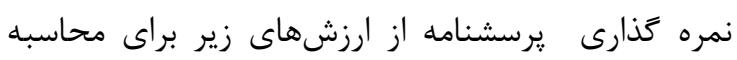

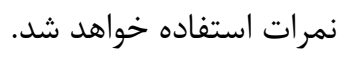
تقريبا هميشه = انمره استفاده خواهد اغلب = Y نمره كاهى اوقات = r نمره بندرت = أ نمره تقريبا هركز = له نمره اگر معلم بين دو طبقه را علامت زد زمره نمره طبقه بالاتر

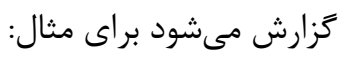

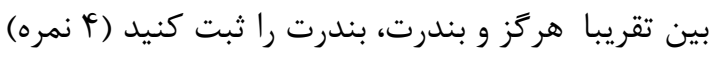

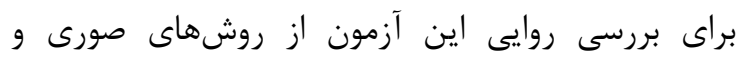

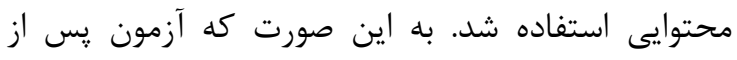
ترجمه به جند متخصص در اين زمينه تحويل داده شد كه آنه

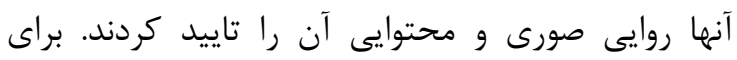
محاسبه يايايى از آلفاى كرنباخ استفاده شد كه براي إئ جهار

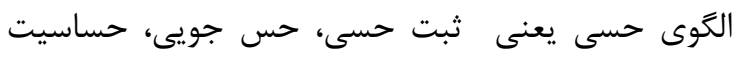

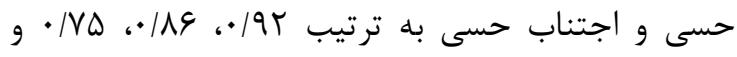
/ / • محاسبه شد كه نشانه همسانى درونى خوب مقياس ترتي

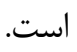
يس از اخذ مجوزهاى لازم و بررسى ملاك هاى ورود به

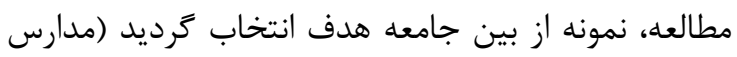

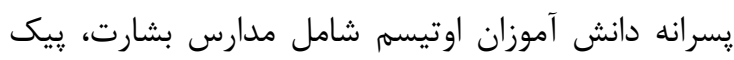

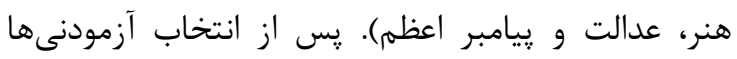

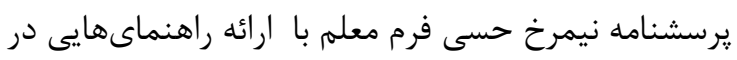

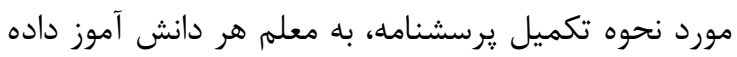

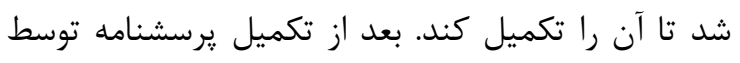

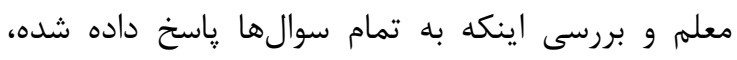

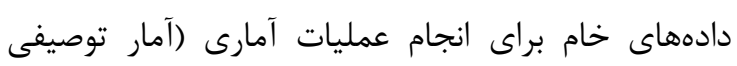

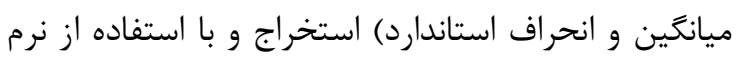

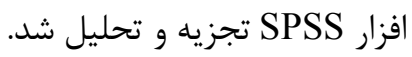

يافتهها براى تجزيه و تحليل داده ها از آمار توصيفى ميانكين و

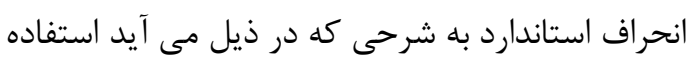
شده است. 
جدول ז: جدول نمرات استاندارد الكوهاى بردازش حسى

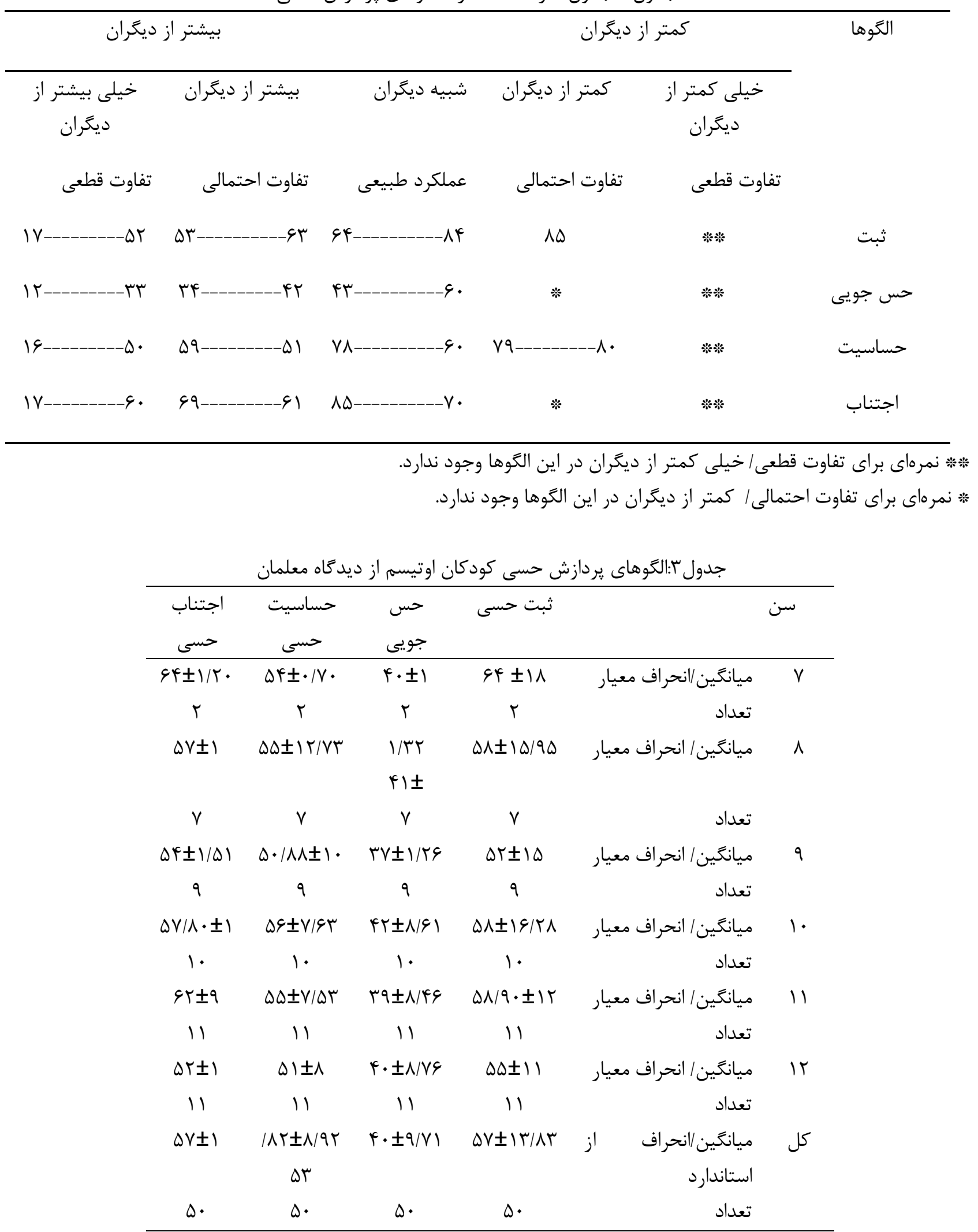


رفتارهاى مشخص مانند خود جرحى و رفتار قالبى نقش

داشته باشد[rV]

\section{نتيجه كيرى}

نياز واضحى براى يزوهش بيشتر در زمينه يردازش حسى

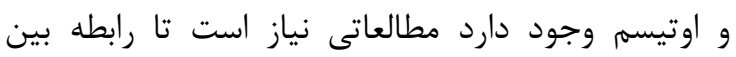

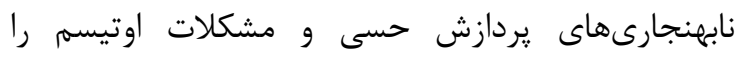

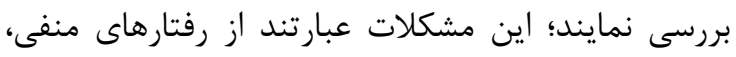

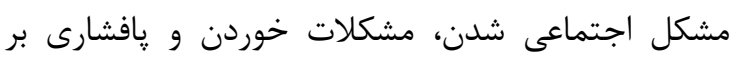
يكسانى محيط. از محدوديتهاى اين يزونه ائن اين است كه توانايىهاى زبانى، هوشى كودكان كنترل نشد و

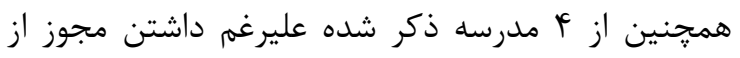

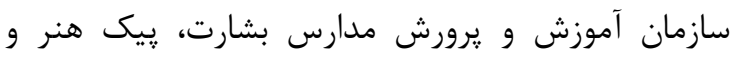

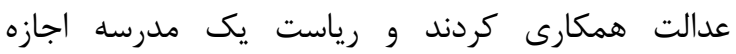

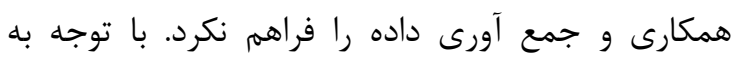

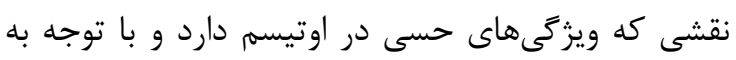

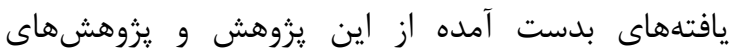
كذشته توجه به اين مقوله از اهميت بسزايى برخوردار

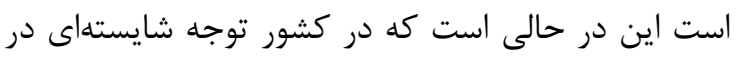
عرصه يزوهشى به اين حيطه نشده است. لذا بريشنهاد إنهاد

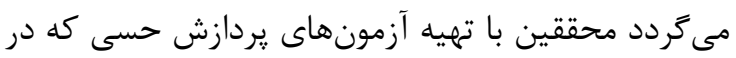

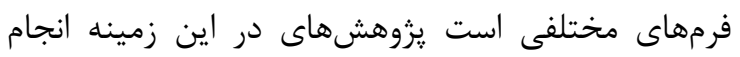

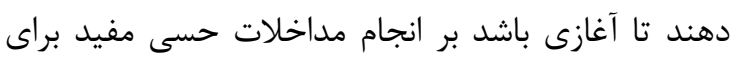
كودكانى كه به اين مداخلات نياز دارند.

\section{تشكر و قدردانى}

بدين وسيله از تمامى كودكان و والدينشان كه اجازه

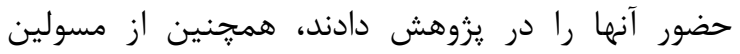

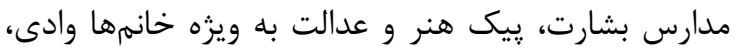
مختارى، و نعمت الهى كمال تشكر و قدر دانى را داريهم.

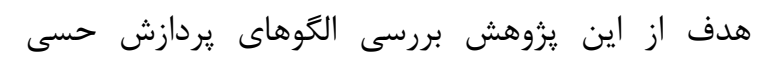

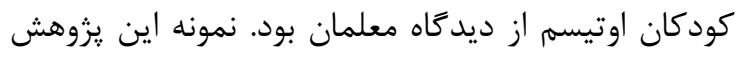

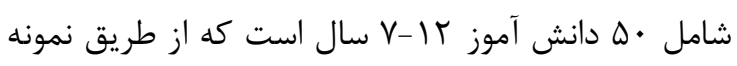

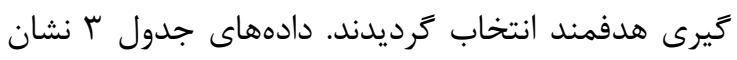

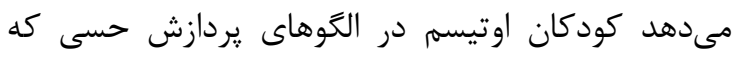

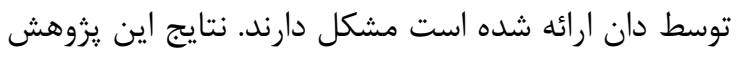

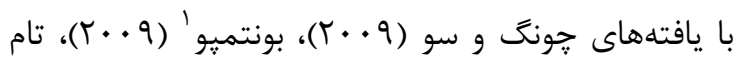

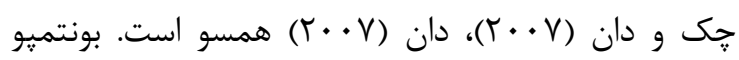

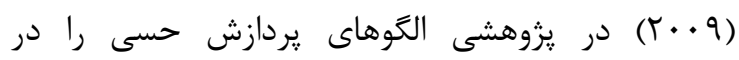
بزركسالان با اختلالهاى طيف اوتيسم در در محيط كار

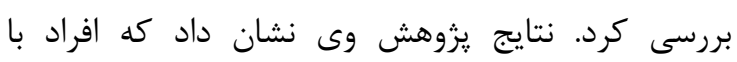

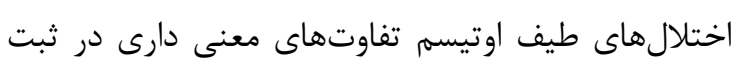

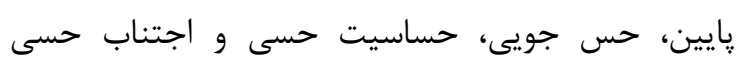

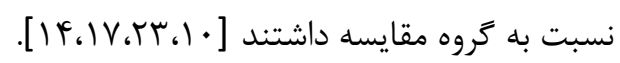

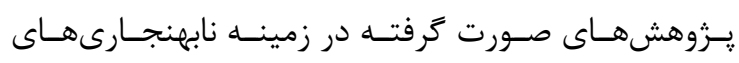

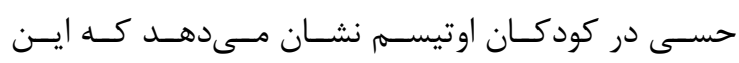

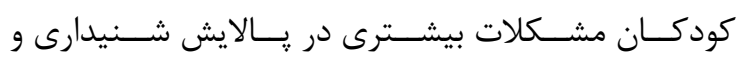

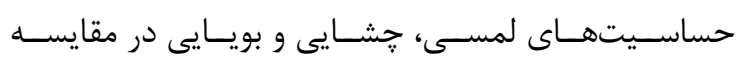

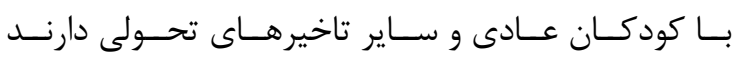

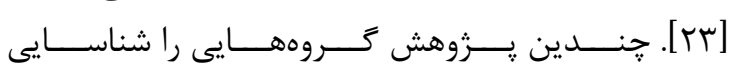

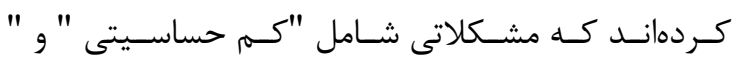

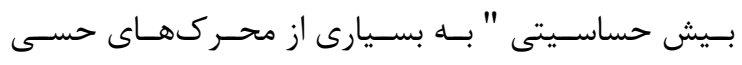

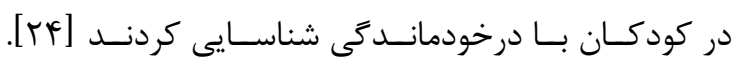

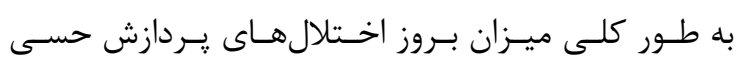

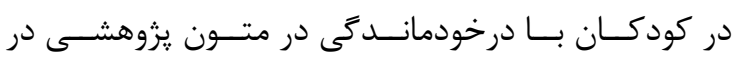

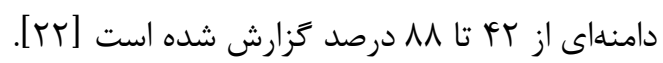

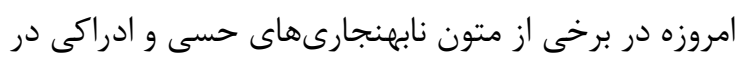

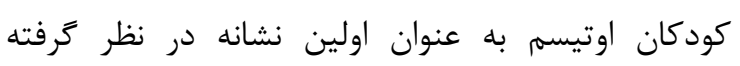

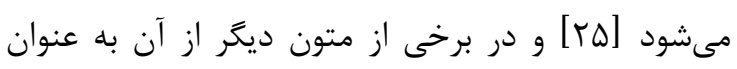

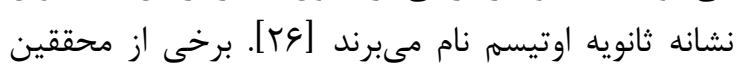

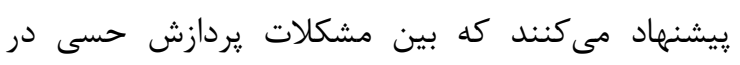

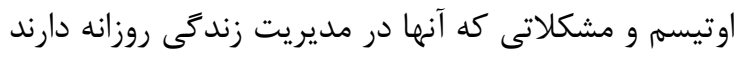

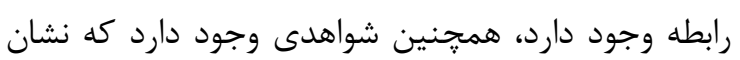

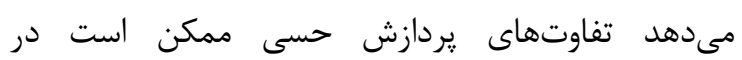

\section{1 - Bontempo}




\section{References}

1. Schiffer R.B, Rao S.M, Fogel B.S, Neuropsychiatry,. Lippincott Williams \& Wilkins 530 Walnut Street, Philadelphia, PA19106 USA, 2003.

2. Hardman, M, Drew C.J, Egan M.W, Human Exceptionality Translated by Alizaheh H, Ganji K, Yousefi Looyeh, Yadegari F, Tehran, Danzhe 2009.

3. Kirk S, Gallagher J.J, Coleman M , Anastasiow N. J, Educating Exceptional children. Wadsworth, 2011.

4. Kern J, Trivedi M.H, Garver C.R, Grannemann B.D, Andrews A.A, Savla J.S, Johnson D.G, Mehta J.A, Schroeder J.L, The pattern of sensory processing abnormalities in autism, Autism 2006; 10 [14]:480-494.

5. Hatami R, evaluation of sensory overresponsivity in children with attention deficit hyperactivity disorder aged 6-11 years referred to occupational therapy clinics in Tehran based on sensory over-responsivity inventory, (Dissertation for the degree of Master of Science), University of social welfare and rehabilitation of science, July 2012[Persian]

6. Schaaf R. C, Miller L. J, Occupational therapy using a sensory integrative approach for children with developmental disabilities, Mental Retardation and Developmental Disabilities Research Reviews (2005); 11[1]: 143-148.

7. Brown N.B, The relation between context and sensory processing patterns in children with autism, (Dissertation for the degree of Master of Science), University of Kansas, 1998.

8. Dunn $\mathrm{W}$, The impact of sensory processing abilities on the daily lives of young children and their families: A conceptual model, Infants and Young Children 1997; 9[3]: 23-35.

9. Dunn W, Supporting children to participation successfully in everyday life by using sensory processing knowledge, Infants and Yong children 2007; 20[1]: 84-101.

10.Roger S, Hepburn S, Wehner E, Parent reports of sensory symptoms in toddlers with autism and those with other developmental disorder, Autism and Developmental Disorders 2003; 33[5]: 631-642.

11.Hochhauser M, Engel-Yeger B, Sensory processing abilities and their relation to participation in leisure activities among children with high-functioning autism spectrum disorder, Research in Autism Spectrum Disorder 2010; 4: 746-754.

12.Kern J, Garver C.R., Carmody T, Andrews A.A, Trivedi M.H, Mehta J.A, Examining sensory quadrants in autism, Research in Autism Spectrum Disorder 2006; 15: 1-9.

13. Cheung P.P.P, Siu A.M.H, A comparison of patterns of sensory processing in children with and without developmental disabilities, Research in Developmental Disabilities 2009; 30: 1468-1480.

14. Schaaf R. C, Miller L. J, Occupational therapy using a sensory integrative approach for children with developmental disabilities, Mental Retardation and Developmental Disabilities Research Reviews 2005; 11[1]: 143-148.

15.Johnson-Ecker C. L, Parham L. D, The evaluation of sensory processing: A validity study using contrasting groups, Journal of Occupational Therapy 1999; 54: 494-503.

16.Bogdashina O, Sensory perceptual issues in autism and asperger syndrome, London and New York: Jessica Kingsley Publishers, 2003. 17. Gartner R, The utilization of environmental modification to improve sensory processing issues for children with asperger's syndrome and other autism spectrum disorders, (Dissertation for the degree of Doctor of psychology), Chicago School. 2011.

18.Ahmadi kahjoogh M, Frahbod M, soortigi $\mathrm{H}$, rasafiani $\mathrm{M}$, sensory processing patterns in children with autism disorder from Winnie Dunn's. Iraninan journal of exceptional children 2012; 10[3]: 385-392[Persian]

19.Biyabangard E, research methods in psychology and educational science, Doran, 2009.

20.Dunn W, sensory profile school companion, Pearson, NCS Pearson, Inc. Printed in the United States of America, 2006.

21.Bontimo $\mathrm{T}$, sensory processing patterns in high-ability adults with autism spectrum disorders in the workplace, (Dissertation for the degree of Doctor of Education), Queen's University, August 2009.

22. Tomchek S.C, Dunn W, Sensory processing in children with and without autism: A comparative study using the short sensory profile. American Journal of Occupational Therapy 2007; 61: 190-200.

23. Wiggins L.D, Robins D.L, Bakeman R, Adamson L.B, Brief report: sensory 
abnormalities as distinguishing symptoms of autism spectrum disorder in young children, Autism developmental disorder 2009; 39: 1087-1091.

24.Hilton C, Graver K, Lavesser P, Relationship between social competence and sensory processing in children with high functioning autism spectrum disorders, Research in Autism Spectrum Disorder 2007; 1:164-173.

25.Roger S, Hepburn S, Wehner E, Parent reports of sensory symptoms in toddlers with autism and those with other developmental disorder, Autism and Developmental Disorders2003; 33 [5]: 631-642.

26. Boyd B.A, McBee M, Holtzclaw T, Baranek G.T, Bodfish J.W, relation among repetitive behaviors, sensory features, and executive function in high functioning autism, Research in autism spectrum disorder 2009; 3: 959-966.

27. Kern J.K, Garver C.R, Carmody T, Andrews A.A, Trivedi M.H, Mehta J, Examining sensory quadrants in autism. Research in autism spectrum disorders 2006; $15: 1-9$. 


\title{
Sensory processing patterns of Autistic children from teachers' point of view
}

\author{
nesaeyan $A^{1} *$, Kazemi $F^{2}$, Pishyare $E^{3}$, Hashemi azar $J^{4}$, Farrokhi $N A^{5}$
}

\begin{abstract}
${ }^{1} \mathrm{Ph} . \mathrm{D}$. student of psychology and Education of exceptional children, Faculty of Educational sciences and Psychology, Allameh Tabataba'I University, Tehran

${ }^{2} \mathrm{Ph}$.D. of psychology, Assistance professor in psychology and Education of exceptional children group, Faculty of Educational sciences and Psychology, Allameh Tabataba'I University, Tehran

${ }^{3} \mathrm{Ph}$.D. of Neuroscience, Assistance professor in Occupational Therapy Department, University of social welfare and rehabilitation science, Tehran

${ }^{4}$ Ph.D. of psychology, Assistance professor in psychology and Education of exceptional children group, Faculty of Educational sciences and Psychology, Allameh Tabataba'I University, Tehran

${ }^{5} \mathrm{Ph} . \mathrm{D}$. of Educational psychology, Assistance professor in psychometric and Educational Psychology group, Faculty of Educational sciences and Psychology, Allameh Tabataba'I University, Tehran
\end{abstract}

* Corresponding Author: Ph.D. student of psychology and Education of exceptional children, Faculty of Educational sciences and Psychology, Allameh Tabataba'I University, Tehran E- mail:

Anesayan1@gmail.com
Abstract

Background \& Objective: the aim of this research was sensory processing patterns of autistic children teachers' point of view.

Mterial \& Method: this research was from descriptive type. Community included all of the student with autism aged 7-12 that studying in 2012-2013 years at school, after entrance criteria sample included 50 student, that selected by purposive sampling. The research tool was Dunn's sensory profile school companion. This tool was completed by teacher for each student. Data were analyzed and presented with descriptive statistic.

Result: the result showed that sensory processing patterns including low registration, sensation sensitivity, and sensation seeking had probable difference and sensation avoidance had definite difference in autistic children.

Conclusion: based on the result autistic children had differences patterns in sensory processing.

Key words: sensory processing patterns, Autistic children

Submitted:16 July 2013

Revised:23 Sep 2013

Accepted:7 Dec 2013 